\title{
打ち切りを含む多因子疼痛試験データの解析
}

\author{
訔山陽二郎, ${ }^{*}, a \quad$ 小宮山 靖, ${ }^{b} \quad$ 塚田秀夫 $c$
}

\section{Analysis of Censored Data in Multi-factorial Analgesic Test}

\author{
Yojiro SaKiYAma, ${ }^{*, a}$ Osamu KomiYAma, ${ }^{b}$ and Hideo TsuKadA ${ }^{c}$ \\ ${ }^{a}$ Research Planning and Coordination, Nagoya Laboratories, Pfizer Global Research and Development, Pfizer Inc., \\ 5-2 Taketoyo-cho, Chita-gun, Aichi 470-2393, Japan, ${ }^{b}$ Statistics and Clinical Programming, Pfizer Global \\ Research and Development, Tokyo Laboratories, Pfizer Japan Inc., 3-22-7, Yoyogi, Shibuya-ku, Tokyo \\ 151-8589, Japan, and 'PET Center, Central Research Laboratory, Hamamatsu Photonics K. K., \\ 5000 Hirakuchi, Hamamatsu City 434-8601, Japan
}

(Received May 23, 2007; Accepted September 3, 2007)

\begin{abstract}
Animal pain testing is essential for the development of new analgesic drugs, where appropriate data analyses as well as appropriate multi-factorial design of experiments are necessary to obtain meaningful results in an efficient fashion. The tail withdrawal experiment is one of the pain tests in which a rhesus monkey is restrained in a chair from which its tail hangs free by so it can be immersed in warm water. The monkeys consistently kept their tails in $38-40^{\circ} \mathrm{C}$ water for an extended period of time, and thus, the data were censored at $120 \mathrm{sec}$. The effect of temperature on the tail withdrawal latency was evaluated using three monkeys with a randomized block design. The effect of morphine on the thermal sensitivity was also evaluated. A Friedman-type two-way analysis of variance (Mack-Skillings test) demonstrated that the effects of both temperature and the animals were significant. The effect of repeated measurement in one animal was not significant using the Friedman test, indicating that the significance of the effect of animals could be attributed to the difference in the intrinsic thermal sensitivity between animals. This method, together with a graphical approach, may prove to be valuable for assessing the sensitivity and reproducibility of an experimental condition, as well as the pharmacological effects of analgesic drugs.
\end{abstract}

Key words_— - pain; analgesic; monkey; Friedman test; Mack-Skillings test

\section{緒言}

優れた鎮痛薬の新規開発を行うためには，非臨床 疼痛試験における適切な実験計画とデー夕解析が必 要不可欠である。非臨床疼痛試験の 1 つに, TWL （tail withdrawal latency：尾退避反応潜時）測定試 験がある．TWL 試験は最初 Janssen らによりラッ トで考案され, ${ }^{1)}$ 以降鎮痛の評価モデルとしてラッ ト，サル2-5)などに広く利用されている．TWL と は, 動物の尾を温浴に浸してから尾を温浴から引き 上げるまでの時間で，侵害性疼痛に対する感受性の 指標である，鎮痛薬により侵害性疼痛のしきい值が 上昇し TWL は延長する。この延長は薬効のよい指

aファイザー侏中央研究所研究企画管理室, $b$ ファイ ザー侏統計・解析部統計コンサルティング室, c浜松ホ トニクス秼中央研究所 PET センター

*e-mail: Yojiro.Sakiyama@ pfizer.com.
標となるが, これを得るためには実験系が高感度で かつ安定である必要がある。すなわち, 温熱刺激に 対する反応が十分に検出でき，かつ繰り返し測定や 個体の変更に対する再現性が高くなければならな い. そこで，まず薬剤を投与しない状態で，温度と 個体の 2 つの因子の効果を事前に明らかにする必要 がある. 一方, 今回測定した TWL 值の特徵として は，温度が高い場合は直ちに尾を温浴から引き上げ るので数秒となるが, 温度が体温付近の場合は温浴 に際限なく尾を浸し続けるため，上限を持った（夕 イプ I の打ち切りのある）測定值となる．このよう に打ち切りを含む応答変数に対しては，正規性を想 定した二元配置分散分析はかならずしも適切ではな $<$, Friedman 型のノンパラメトリック二元配置分 散分析（Mack-Skillings 検定）の方が望ましい。し かし，その適用事例についてはほとんど知られてい ない。本稿では，2つの因子を有する非臨床疼痛試 
験を事例として，Mack-Skillings 検定の適用方法に ついて紹介する.

$$
\text { 方法 }
$$

本実験は，浜松ホトニクス中央研究所動物実験倫 理委員会の承認を得て実施した。また，サルの飼育 及び実験に関しては US National Institute of Health の推奨基準及び浜松ホトニクス中央研究所のガイド ラインに準拠して実施した。

1. 材料動物は浜松ホトニクス侏中央研究所 が所有する雄性アカゲザル（Macaca mulatta） 3 匹 (体重 4.4-8.3 kg), 週 2 回 3 力月以上のチェアート レーニングを施されたものを覚醒状態で使用した。 覚醒状態におけるサルの使用に関しては塚田らの方 法に従った. ${ }^{6,7)}$ サルの尾は先端から $10 \mathrm{~cm}$ 以上剃毛 して，モンキーチェアーに固定した。

薬剤は塩酸モルヒネ (morphine hydrochloride, $10 \mathrm{mg} / \mathrm{ml}$ ，塩野義）を用いた。

\section{2. 尾退避潜時（tail withdrawal latency）の測定} 実験の概観を Fig. 1 に示す。一定温度に保った水 道水の入った容器を用意し, チェアーに覚醒状態の まま固定されたサルの尾の先端約 $10 \mathrm{~cm}$ をその中 へ浸し，直ちに手を離してから尾が自発的に退避す るまでの時間を TWL とした。水道水の温度は 37 ${ }^{\circ} \mathrm{C}, 39^{\circ} \mathrm{C}, 41^{\circ} \mathrm{C}, 43^{\circ} \mathrm{C}, 45^{\circ} \mathrm{C}, 47^{\circ} \mathrm{C}, 50^{\circ} \mathrm{C}$ 及び $55^{\circ} \mathrm{C}$ の 8 通りをそれぞれ 1 回ずつ実施しこれを 1 ブロッ クとし，個体当たり 4 ブロック行った。ブロック内 では実験は無作為化した，すなわち乱塊法（randomized block design）として実施した。測定の間

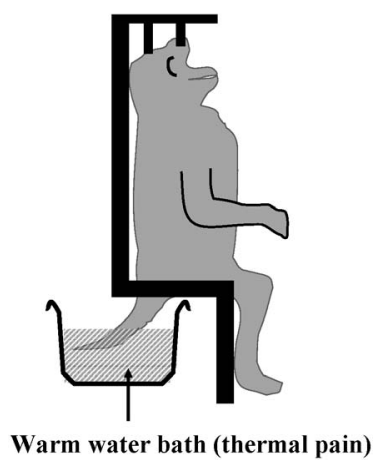

Fig. 1 Schematic Representation of a Tail Withdrawal Experiment in which a Monkey Sit on a Dedicated Monkey Chair

The tail was immersed in a warm water bath for thermal pain stimulation, followed by the measurement of tail withdrawal latency. The temperature was preliminarily adjusted with various ranges.
隔は 10 分空け, 合計で $8 \times 4=32$ 回の刺激を 1 個体 当たりに行った．実験は午前に 4 時間，午後に 4 時 間，合計 8 時間実施しその日のうちに実験を終了し た．別の日に，別の個体を同じ要領で実施した。こ れを 3 個体について実施した。打ち切りの cut off 值は 120 秒とした。

3. モルヒネによる鎮痛効果の検討 上記で用 いた 3 個体につき，モルヒネによる鎮痛効果の検討 を行った。個体は覚醒状態のままチェアーに固定 し，橈側皮静脈にカテーテルを留置した。塩酸モル ヒネ $1 \mathrm{mg} / \mathrm{kg}$ を留置カテーテルから静脈内投与し た．刺激温度は先の疼痛試験の結果より，尾を引く 反応が十分速くかつ動物に過度の負荷を与えない温 度として $47^{\circ} \mathrm{C}$ が適切であると判断しこれを適用し た. TWL の測定はモルヒネ投与の 30 分前, 0 分 (薬剂投与直前), 30 分後, 60 分後, 120 分後, 240 分後の 6 点で行った。

4. 繰り返しを含む 2 元配置 Friedman 型順位検 定（Mack-Skillings 検定） 本試験における応答 変数である TWL には打ち切りがあるため, 分布の 正規性を想定することはかならずしも適切でない． このような場合，因子の効果を検定するにはノンパ ラメトリック法の方が望ましい。ささら本実験のよ うに温度，個体と因子が 2 つありまた繰り返しを持 つ場合は，以下に述べるような Mack と Skillings らにより考案された繰り返し有りの 2 元配置 Friedman 型順位検定（Mack-Skillings 検定）を行えばよ い. ${ }^{8)}$ まず，「 $H_{0}$ ：処置による変化がない」を帰無 仮説とする，処置とはここではいろいろな温度の刺 激を与えたり，個体を変えたりするなどの一連の実 験処置に相当する。観測值を $n$ 個のブロックに分 け，ブロック毎に順位変換を行う。各ブロックには $k c$ 個（ $k$ は処置数， $c$ は繰り返し数）の観測値があ る。観測值の総数は $N=n k c$ 個となる。いま, $i$ 番 目のブロック $(i=1, \cdots, n)$ における $j$ 番目の処置 $(j=1, \cdots, k)$ において $q$ 回の繰り返し $(q=1, \cdots$, c) を行ったとする. $r_{i j q}$ を $X_{i j q}$ のブロック内順位と すると, $j$ 番目の処置における平均順位和 $S_{j}$ は以下 の式で表される.

$$
S_{j}=\sum_{i=1}^{n}\left[\sum_{q=1}^{n} r_{i j q} / c\right], \text { for } j=1, \cdots, k .
$$

ついで, Mack-Skillings（MS）統計量は以下の式で 与えられる。 


$$
\begin{aligned}
M S & =\left[\frac{12}{k(N+n)}\right] \sum_{j=1}^{k}\left[S_{j}-\frac{N+n}{2}\right]^{2} \\
& =\left[\frac{12}{k(N+n)}\right]\left\{\sum_{j=1}^{k} S_{\mathrm{j}}^{2}\right\}-3(N+n)
\end{aligned}
$$

別途で, $k$ を処置数, $c$ を繰り返し数, $n$ をブロ ック数, $\alpha$ を有意水準としたときの革却限界值を付 表8,9) で求めこれを $m s_{\alpha}$ としたとき, $M S \geq m s_{\alpha}$ の とき $H_{0}$ は棄却され，処置による変化が有意とな る。なお， $c=1$ とした繰り返しのない場合が Friedman 検定に相当する。言い換えれば Friedman 検定は広義の Mack-Skillings 検定である.

ここでは，個体と温度を 2 因子とした効果の検定 を行つた. 「 $H_{0 a}$ : 個体による変化がない」を帰無仮 説としたときの Mack-Skillings 検定 $(k=3, n=5, c$ $=4)$, 及び $「 H_{0 b}$ : 処置（温度）による変化がない」 を帰無仮説としたときの Mack-Skillings 検定（ $k=$ $3, n=5, c=4)$ を実施した.

また，同一個体でも測定の繰り返しによる効果が あるかどうかを確認したい。そこで，用いた 3 匹の 個体のそれぞれについても繰り返しと温度を 2 因子 とした効果の検定を行った。 「 $H_{0 c}-H_{0 e}$ ：それぞれの 個体で繰り返しによる変化がない」を帰無仮説とし たときの Friedman 検定 $(k=4, n=5, c=1)$, 及び $\left\ulcorner H_{0 f}-H_{0 h}\right.$ : それぞれの個体で温度による変化がな い」を帰無仮説としたときの Friedman 検定（ $k=$ $5, n=4, c=1)$ を実施した.

検定には, eq. (2)で計算した MS 值と，棄却限界 值 (正確值) ${ }^{8,9)}$ を用い比較した. MS 值>革却限界 值であれば因子の効果は有意であるとした。 また萧 却限界值の近似值として $\chi^{2}(0.05, k-1)$ を計算しこ れとも比較した。

\section{結果}

\section{1. 尾退避反応潜時 (TWL: tail withdrawal laten-}

cy）の測定 実験の結果, $37^{\circ} \mathrm{C}-45^{\circ} \mathrm{C}$ において は，ほとんどが 120 秒に達し，この範囲で最も高温 の $45^{\circ} \mathrm{C}$ においても, 12 回の測定中 11 回は 120 秒 に達していた。 したがって, $37^{\circ} \mathrm{C}-41^{\circ} \mathrm{C}$ のデー夕は 因子の効果を評価する上で圥長なデータであると判 断し除外した。 そして，Table 1 に示すように，43 ${ }^{\circ} \mathrm{C}-55^{\circ} \mathrm{C}$ のデータのみを解析の対象とした。 TWL と刺激温度との関係は Table 1 及び Fig. 1 に示すよ うに，どの個体においても高温になるにつれ TWL
Table 1. Results TWL Measurement with Three Monkeys

\begin{tabular}{clrrrrr}
\hline \hline Factor & & $43^{\circ} \mathrm{C}$ & $45^{\circ} \mathrm{C}$ & $47^{\circ} \mathrm{C}$ & $50^{\circ} \mathrm{C}$ & $55^{\circ} \mathrm{C}$ \\
\hline & 1st & 120 & 120 & 120 & 5 & 3 \\
Monkey A & 2nd & 120 & 120 & 4 & 2 & 2 \\
& 3rd & 120 & 120 & 60 & 3 & 2 \\
& 4 th & 120 & 120 & 63 & 6 & 1 \\
\hline & 1st & 120 & 5 & 5 & 1 & 2 \\
Monkey B & 2nd & 120 & 120 & 6 & 4 & 2 \\
& 3rd & 120 & 120 & 3 & 2 & 1 \\
& 4 th & 24 & 120 & 10 & 1 & 1 \\
\hline & 1 st & 120 & 120 & 120 & 19 & 2 \\
Monkey C & 2nd & 120 & 120 & 120 & 2 & 3 \\
& 3 rd & 120 & 120 & 14 & 3 & 3 \\
& 4 th & 120 & 120 & 6 & 100 & 3 \\
\hline Factor & & $43^{\circ} \mathrm{C}$ & $45^{\circ} \mathrm{C}$ & $47^{\circ} \mathrm{C}$ & $50^{\circ} \mathrm{C}$ & $55^{\circ} \mathrm{C}$ \\
\hline Mean & & 112.0 & 110.0 & 44.3 & 12.3 & 2.08 \\
S.D. & & 27.7 & 33.2 & 50.2 & 28.0 & 0.79 \\
\hline
\end{tabular}

が短くなり， $50^{\circ} \mathrm{C}$ 以上ではほとんどが数秒の TWL であった。 また，反応が著明に変化しようとする $47^{\circ} \mathrm{C}$ 付近においては大きな個体差が認められた.

例えば 4 回の反復測定において，個体 B はどの測 定も数秒で反応したが，個体 $\mathrm{A}$ 及び C では数秒一 120 秒以上の大きな変動を示した。平均值（Fig. 2 の線）でみても，個体 $\mathrm{A}$ ，個体 $\mathrm{C}$ に比べ個体 $\mathrm{B}$ （点線）の高い温度感受性が認められた。標準偏差 はどの個体においても温度により大きく異なり，ま た同じ温度でも個体毎に大きく異なっていた。

2. モルヒネによる鎮痛効果の検討 Figure 3 に示すように，上記いずれの個体においても，モル ヒネ投与前は TWL は数秒であったのに対し，モル ヒネ投与後は TWL が時間とともに増加し， 1 時間 以降は 2 匹の動物で 120 秒まで達した。

3. Mack-Skillings 検定 Mack-Skillings 検定 の結果を Table 2 に示す。結果として，個体，温度 のいずれの因子についても MS 值は棄却限界值よ りも大きく，有意であることが判明した。また棄却 限界值の正確值は近似值に比べ若干小さいがほぼ近 い值となり，判定結果も同一であった。また，各個 体について Friedman 検定を行つた結果もまとめて Table 2 に示す. どの個体についても 4 回の繰り返 しの効果は有意でないこと，また温度の効果は有意 であることが判明した。 
A

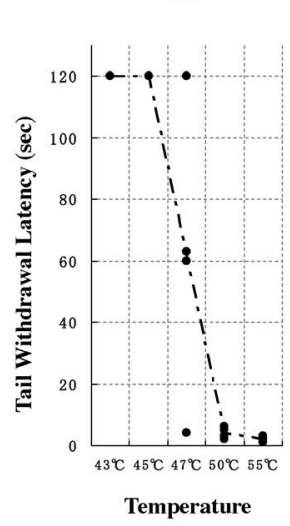

B

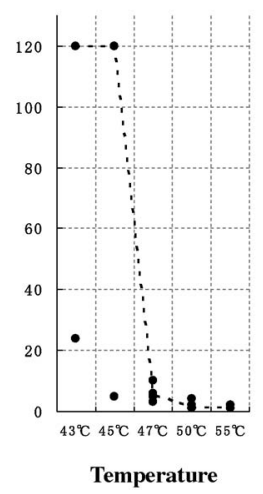

C

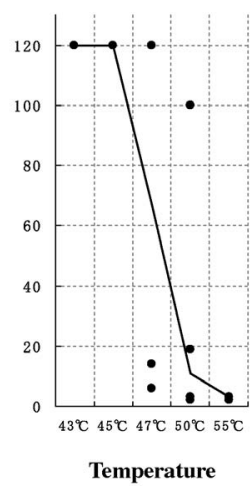

Fig. 2 Tail Withdrawal Latencies in Three Individual Monkeys, Monkey A, B and C

Dots denote individual values obtained, and lines denote medians within each temperature. Cutoff of TWL was set at 120 seconds.

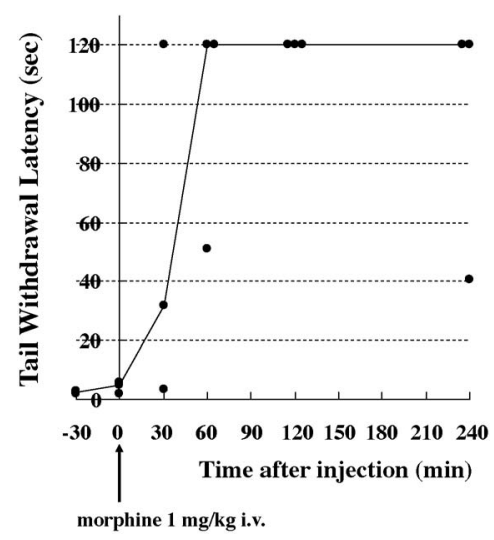

Fig. 3 The Effect of Intravenous Injection of Morphine (1 mg/ $\mathrm{kg}$ ) on the Tail Withdrawal Latencies in Three Monkeys

Dots denote individual values obtained, and a line denotes medians within each time.

\section{考察}

TWL を痛みのエンドポイントとして鎮痛薬の薬 効評価に利用するためには，まず薬を投与しない状 態で TWL が刺激温度に応じて変化すること，また TWL が個体内での繰り返し及び個体間で再現性が 保たれていることが必要である. Figure 2 のグラフ で明らかな通り，いずれの個体においても温度を上 げていくと $45^{\circ} \mathrm{C}$ まではほとんご反応がなく上限值 （120 秒）まで達したが， $47^{\circ} \mathrm{C}$ 付近を境界に著明な 尾の退避反応が出現し，50学以上ではほとんどが 数秒で退避した。この変化はどの個体にも共通して おり，また，各個体における 4 回の測定の変動も $47^{\circ} \mathrm{C}$ を除いては比較的小さかった。一方 $47^{\circ} \mathrm{C}$ の結 果をみると，個体 B は 4 回の測定がすべて数秒の
Table 2. Results of Two-way Layout Nonparametric Test

\begin{tabular}{|c|c|c|c|c|}
\hline \multirow{2}{*}{$\begin{array}{c}\text { Null } \\
\text { hypothesis }\end{array}$} & \multirow[b]{2}{*}{ MS } & \multicolumn{2}{|c|}{ Critical Value } & \multirow[b]{2}{*}{ Judgment } \\
\hline & & Exact & $\begin{array}{l}\text { Approximation } \\
\qquad\left(\chi^{2}\right)\end{array}$ & \\
\hline $\mathrm{HOa}$ & 10.27 & $\begin{array}{c}5.98 \\
(\alpha=0.051)\end{array}$ & $\begin{array}{c}5.99 \\
(\alpha=0.05, \mathrm{df}=2)\end{array}$ & Significant \\
\hline $\mathrm{HOb}$ & 43.26 & $\begin{array}{c}9.30 \\
(\alpha=0.050)\end{array}$ & $\begin{array}{c}9.49 \\
(\alpha=0.05, \mathrm{df}=4)\end{array}$ & Significant \\
\hline $\mathrm{H} 0 \mathrm{c}$ & 2.70 & $\begin{array}{c}7.32 \\
(\alpha=0.055)\end{array}$ & $\begin{array}{c}7.81 \\
(\alpha=0.05, \mathrm{df}=3)\end{array}$ & $\begin{array}{l}\text { Not } \\
\text { significant }\end{array}$ \\
\hline HOd & 2.58 & $\begin{array}{c}7.32 \\
(\alpha=0.055)\end{array}$ & $\begin{array}{c}7.81 \\
(\alpha=0.05, \mathrm{df}=3)\end{array}$ & $\begin{array}{l}\text { Not } \\
\text { significant }\end{array}$ \\
\hline $\mathrm{HOe}$ & 0.06 & $\begin{array}{c}7.32 \\
(\alpha=0.055)\end{array}$ & $\begin{array}{c}7.81 \\
(\alpha=0.05, \mathrm{df}=3)\end{array}$ & $\begin{array}{l}\text { Not } \\
\text { significant }\end{array}$ \\
\hline HOf & 13.80 & $\begin{array}{c}8.80 \\
(\alpha=0.049)\end{array}$ & $\begin{array}{c}9.49 \\
(\alpha=0.05, \mathrm{df}=4)\end{array}$ & Significant \\
\hline $\mathrm{H} 0 \mathrm{~g}$ & 13.90 & $\begin{array}{c}8.80 \\
(\alpha=0.049)\end{array}$ & $\begin{array}{c}9.49 \\
(\alpha=0.05, \mathrm{df}=4)\end{array}$ & Significant \\
\hline $\mathrm{HOh}$ & 11.35 & $\begin{array}{c}8.80 \\
(\alpha=0.049)\end{array}$ & $\begin{array}{c}9.49 \\
(\alpha=0.05, \mathrm{df}=4)\end{array}$ & Significant \\
\hline
\end{tabular}

H0a: No differences among the effect of monkey, H0b: No differences among the effect of temperature, H0c: No differences among the effect of repeated measurement in monkey A, HOd: No differences among the effect of repeated measurement in monkey B, H0e: No differences among the effect of repeated measurement in monkey $\mathrm{C}, \mathrm{HOf}$ : No differences among the effect of temperature in monkey A, HOg: No differences among the effect of temperature in monkey B, HOh: No differences among the effect of temperature in monkey $\mathrm{C}$.

反応であったが，個体 A と C ではデータが数秒と 120 秒の両極に分かれた。これらの結果から，個体 $\mathrm{B}$ は個体 A, C に比べ刺激に対する感受性の高い個 体であることが示唆された。こうした示唆は，それ ぞれ 1 回きりの測定では見逃す可能性があり，その 意味で個体内の繰り返し測定を行うことは重要であ る.

このように, グラフ化して個々の観測值の挙動を 考察することはまず重要であるが, 次に全体として の因子の効果はどのように評価したらよいか，通常， 2 つの因子を含む場合は 2 元配置の（繰り返し有り の）分散分析を行えばこれらの誤差の評価は可能で ある。しかし今回のデータの特徵として, 上限值 (120 秒) と下限值（数秒）付近は変動が比較的小 さく, 反応が切り替わる $47^{\circ} \mathrm{C}$ 付近では変動が特に 大きい。それぞれの処置（温度）での平均值からの 残差から全体の尖度と歪度を計算すると, 尖度= 4.0, 歪度 $=-0.1$ となった. したがって, デー夕の 分布は全体として大きな歪みはないものの, 120 秒 及び数秒に值が集中した尖りの大きい分布であると 考えられる.このような分布では正規性の想定は困 
難であるため，分散分析などのパラメトリックな解 析手法はかならずしも適切ではなく，分布を仮定し ないノンパラメトリックな手法を適用する方が望ま しいと考えられる。そして今回のように 2 因子で繰 り返しも含まれている場合は，2 元配置の MackSkillings 検定が有効である．検定の結果は Table 2 に示した通り，MS 值が棄却限界值を超え有意とな り，全体として個体の効果，温度の効果いずれも有 意という結論になつた。また各個体で繰り返しと温 度を 2 因子とする Friedman 検定（繰り返しなしの Mack-Skillings 検定）を行ったところ，どの個体に ついても温度の効果は有意となつたが繰り返しの効 果は有意とならなかった。よって, 繰り返しに伴う 系統誤差などの変動は十分に制御されており，用い た 3 匹の個体間の変動は, 温度に対する個々の個体 固有の感受性の相違に基づくものであると推測され る.このように，打ち切りを含むデー夕において複 数の因子の効果を推測するのに, Mack-Skillings 検 定は有効な手法である．Mack-Skillings 検定は広く 知られた手法ではないが，最近になって，マイクロ アレイ実験における発現遺伝子の特定などに使われ 始めている。 ${ }^{10)}$

精度の高い定量計測を実現するためには，個々の サルで繰り返し測定を行うことが重要であることは 言うまでもないが，それに加え今回のように各ブロ ック内で各温度 1 回ずつの乱塊法の実験デザインに することにより，高温の刺激がある時間に集中し感 作・脱感作が起こるといつた問題を回避することが できる．実験手技上も刺激と刺激の間を 10 分空け るなどの工夫を行うとより望ましい。例えば $47^{\circ} \mathrm{C}$ 付近の変動に関して, Table 1 の Monkey A では, 1 回目は 120 秒， 2 回目は 4 秒であったが 3 回目以 降は 60 秒以上であった。したがって，この変動は 感作などの影響を含んだ系統的なものではないと考 えられる，逆に次第に TWL が短くなるなど系統的 な変化が認められた場合には, 誤差の原因を考慮し た実験デザインの見直しが必要となるであろう。今 回の例では，未梢における侵害受容の自由神経終末 からの入力レベルの差異によって生じ得る誤差は回 避できたと考えられるが，それ以外にも，内因性の 誤差としてはより高位中枢での痛覚伝導メカニズム の差異, 嫌悪条件付け（刺激による不快を学習し尾 が退避し易くなる）などが考えられる。これらは制
御が非常に困難な変動因子であるから，本実験を行 う前に，実験動物選定時に簡単な予備試験を行い， 反応の過敏な個体を除去するなどの工夫が必要とな るであろう。また外因性の誤差の考慮も重要であ る。実験時の室温，照明などは言うまでもないが， 注意すべきは日内変動，日間変動の影響である．今 回は 1 匹当たり 32 回の計測で丸 1 日を要している ので，個体を変更すると日間変動の影響は不可避と なる，仮に計測回数を半分にできるとしたら，午前 と午後に分けた実験を行うことになり，日間変動は 回避できるが今度は日内変動の問題が起こる。この ような場合は，クロスオーバーデザインにするなど の工夫が必要であろう。そして何より重要なこと は，想定される変動因子をできる限り制御すること である．今回の 3 日間の実験に際しては，実験者や 分担，手順等は固定し，手技や実験室環境等は 3 日 とも極力同じ条件になるように努めた。例えば刺激 に用いる温浴を準備して尾に刺激を与えるまでの操 作に手間取ると，その間に温浴の温度が低下するの で，これらを常に同じ時間間隔で実行する，など細 かい実験上の配慮の積み重ねが重要となることは言 うまでもない.

中型・大型動物を用いた薬理試験においては，完 全ランダム化実験では個体の変更に手間が掛かるゆ えに分割実験の型式が取られる場合が多い。今回の モルヒネを用いた検討でも，まずある個体で薬効評 価を含む実験を一通り済ませてから，次の個体で実 験を行った。これにより，薬物処理の前值と後值の 同一個体での比較が可能となり，Fig. 3 に示したよ うな薬物効果の経時的追跡が可能となる。ここでも 時間と個体を因子とする Friedman 検定を行った結 果，検定統計量 $\mathrm{MS}=11.67$ ，棄却限界值 $\chi^{2}(0.05,5)$ $=11.07$ で，時間の効果が有意となりモルヒネによ る鎮痛作用の発現が確認された。今回はモルヒネ 1 用量での検討であったが，複数の鎮痛薬で反応を比 較したり用量反応関係を検討したりする場合は，薬 物若しくは用量という因子がさらに 1 つ増えること になる。 その場合も Mack-Skillings 検定により因子 の効果を評価することが可能となる.

複数個体で繰り返しを含む動物実験では，通常繰 り返しありの 2 元配置分散分析が適用されるが，今 回のように正規性を仮定できない動物実験データに おける Mack-Skillings 検定の適用は，応用事例とし 
ては新しいといえる. 特に大型・中型動物を扱う薬 理研究者は同一個体での繰り返し測定を行うことが 多く, これと類似の問題に遭遇する可能性があり, その際の指針を与え得るものである。また，今回 Mack-Skillings 検定に加え各個体について Friedman 検定を適用し, 繰り返しと温度の効果の判定 を行った。 そして，どの個体についても繰り返しの 効果が有意でないことから, 繰り返しに伴う系統誤 差などの変動は十分に制御されており, 温度に対す る個々の個体の感受性の相違が全体としての個体の 効果に反映していることを示唆することができた. こうした 2 本立てのアプローチにより因子の効果を 考察する試みも十分応用可能と考えられる.

今回のような打ち切りを含んだデー夕を解析する 際には，正規性を想定したパラメトリックな解析は かならずしも適切でなく，ノンパラメトリック解析 が望ましい。一方，ノンパラメトリック解析は簡便 ではあるものの，観測値を順序に変換するため生物 学的に重要と思われる量的情報までもが削ぎ落とさ れるという久点もある。また仮説検定という方法 は，「反応が因子によって変わらない」という仮説 が，実際に観測したデー夕から否定できるかどうか を判定するものである．これに対し，反応が因子に よりどのように変化するかを定量的客観的に示した いのであれば，薬理学的洞察に基づき非線形関数 （非線形モデル）を当てはめパラメータを推定する 方法が有効である。 今回の例でも，打ち切りを考慮 した非線形モデルによる解析が可能であれば，得ら れた結果をより定量的客観的に示すことができると 考えられ，今後の検討課題である.
謝辞 本実験の推進に御協力頂いた浜松ホト二 クス中央研究所 PET センターの皆様に感謝申し上 げます。

\section{REFERENCES}

1) Janssen P. A., Niemegeers C. J., Dony J. G., Arzneimittelforschung, 13, 502-507 (1963).

2) Dykstra L. A., Gmerek D. E., Winger G., Woods J. H., J. Pharmacol. Exp. Ther., 242, 413-420 (1987).

3) Dykstra L. A., Woods J. H., J. Pharmacol. Methods, 15, 263-269 (1986).

4) Sewell R. D., Spencer P. S., Neuropharmacology, 15, 683-688 (1976).

5) Van Bever W. F., Niemegeers C. J., Schellekens K. H., Janssen P. A., Arzneimittelforschung, 26, 1548-1551 (1976).

6) Tsukada H., Miyasato K., Kakiuchi T., Nishiyama S., Harada N., Domino E. F., Synapse, 45, 207-212 (2002).

7) Tsukada H., Miyasato K., Nishiyama S., Fukumoto D., Sato K., Kakiuchi T., Domino E. F., Neuropsychopharmacology, 30, 21442153 (2005).

8) Mack G. A., Skillings J. H., J. Am. Statist. Assoc., 75, 947-951 (1980).

9) Hollander M., Wolfe D. A., Nonparametric Statistical Methods, Wiley Series in Probability and Statistics, 2nd ed.: John Wiley \& Sons, Inc., 328-332 (1999).

10) Barrera L., Benner C., Tao Y. C., Winzeler E., Zhou Y., BMC Bioinformatics, 5, 42 (2004). 